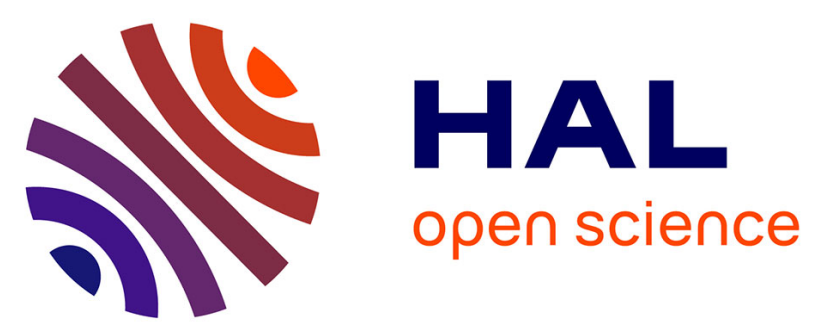

\title{
Mechanical properties of nanostructured films with an ultralow volume fraction of hard phase
}

\author{
Marion Chenal, Cyril Véchambre, J.-M. Chenal, Laurent Chazeau, Vincent
} Humblot, Laurent Bouteiller, Costantino Creton, Jutta Rieger

\section{- To cite this version:}

Marion Chenal, Cyril Véchambre, J.-M. Chenal, Laurent Chazeau, Vincent Humblot, et al.. Mechanical properties of nanostructured films with an ultralow volume fraction of hard phase. Polymer, 2017, 109, pp.187-196. 10.1016/j.polymer.2016.12.043 . hal-01421077

\section{HAL Id: hal-01421077 https://hal.sorbonne-universite.fr/hal-01421077}

Submitted on 21 Dec 2016

HAL is a multi-disciplinary open access archive for the deposit and dissemination of scientific research documents, whether they are published or not. The documents may come from teaching and research institutions in France or abroad, or from public or private research centers.
L'archive ouverte pluridisciplinaire HAL, est destinée au dépôt et à la diffusion de documents scientifiques de niveau recherche, publiés ou non, émanant des établissements d'enseignement et de recherche français ou étrangers, des laboratoires publics ou privés. 


\section{Mechanical properties of nanostructured films with an ultralow volume fraction of hard phase}

Marion Chenal ${ }^{1,2}$, Cyril Véchambre ${ }^{3}$, Jean-Marc Chenal $^{3}$, Laurent Chazeau ${ }^{3}$, Vincent Humblot $^{4}$, Laurent Bouteiller ${ }^{1,2}$, Costantino Creton $^{5,6,7}$, Jutta Rieger ${ }^{1,2} *$

${ }^{1}$ Sorbonne Universités, UPMC Univ Paris 06, UMR 8232, IPCM, Chimie des Polymères, F75005, Paris, France

${ }^{2}$ CNRS, UMR 8232, IPCM, Chimie des Polymères, F-75005, Paris, France

${ }^{3}$ INSA-Lyon, MATEIS CNRS, UMR 5510, F-69621, Villeurbanne, France

${ }^{4}$ Sorbonne Universités, UPMC Université Paris 06, UMR 7197-CNRS, Laboratoire de Réactivité de Surface (LRS), 4 place Jussieu, F-75252 Paris Cedex 05, France

${ }^{5}$ Laboratoire SIMM, CNRS, ESPCI Paris, PSL Research University, 10 rue Vauquelin, Paris, France.

${ }^{6}$ Laboratoire SIMM, Université Pierre et Marie Curie, Sorbonne-Universités, 10 rue

Vauquelin, Paris, France

${ }^{7}$ Global Station for Soft Matter, Global Institution for Collaborative Research and Education, Hokkaido University, Sapporo, Japan

* Author to whom correspondence should be addressed. E-mail: costantino.Creton@espci.fr, jutta.rieger@upmc.fr

Keywords: RAFT Polymerization, Film, Nanostructure, Core-shell latexes, Mechanical properties 


\section{Graphical abstract}

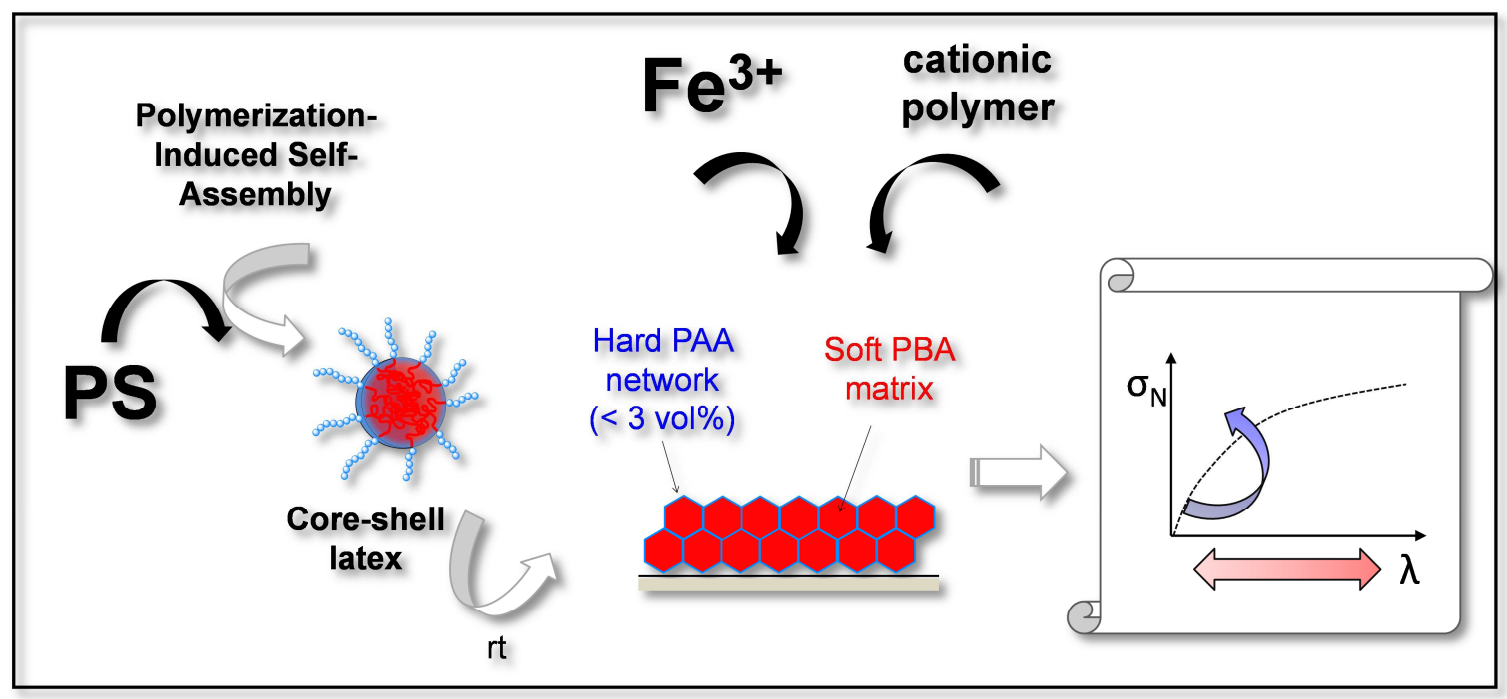

\section{Abstract}

We demonstrate in this paper how polymerization induced self-assembly (PISA) using RAFT can be used to synthesize very asymmetric but monodisperse poly(acrylic acid)- $b$-poly $(n$ butyl acrylate) block copolymers, PAA- $b$-PBA, with a short PAA block and a long PBA block. In the course of the surfactant-free emulsion polymerization, core-shell particles form in water, with the short hydrophilic block located at the water-particle interface, and the long hydrophobic block constituting the particle core. Drying at room temperature creates films possessing an out of equilibrium structure, where the glassy PAA block generates a percolating network of shells. When deformed in uniaxial elongation, these films combine a high stiffness in small strains (considering the low volume fraction of PAA, of only $3 \mathrm{wt} \%$ ), a yield stress and a significant extensibility before failure. The modulus, yield stress and extensibility can be tuned by modifying the composition of the latex serum with cations or positively charged low molar mass polymers, or by changing the copolymer composition. Of particular interest was the synthesis by PISA of particles of triblock copolymer PAA- $b$-PBA$b$-PS. The out of equilibrium structure obtained had a very interesting combination of high stiffness, extensibility and high fracture toughness. 


\section{Introduction}

Obtaining stiffer rubbery materials without sacrificing extensibility and reversibility of the deformation is a classical objective of polymer science. A very efficient way to do so is to design a percolating hard domain into a predominantly soft material. ${ }^{1-5}$ At small deformations the stress is carried by the stiff network while as the deformation increases, the percolating structure breaks and the load is sustained by the soft domains which can be very extensible. This general strategy has been used for example in double interpenetrated networks where two polymers are synthesized sequentially ${ }^{6,7}$ but also in nanocomposites. ${ }^{8,}{ }^{9}$ However for processing reasons it would be desirable to make such stiff but extensible materials in a single synthesis and drying step. One attractive strategy is to prepare materials through the selfassembly of colloidal systems, ${ }^{10}$ synthesized by aqueous emulsion polymerization ${ }^{11,} 12$ to create a percolating structure made of thin but hard walls between deformable particles. This approach combines the attractiveness of replacing organic solvent by water, with an easy, efficient and straightforward method to create core-shell particles. ${ }^{13},{ }^{14}$ Although qualitatively the principle is demonstrated, it remains challenging to combine a high degree of stiffening (increase by one order of magnitude) while maintaining several hundred percent extensibility, using only a very low volume fraction of a hydrophilic hard phase and little or no surfactants to maintain water resistance.

We have recently shown that highly asymmetric poly(acrylic acid)- $b$-poly( $n$-butyl acrylate) block copolymers (PAA- $b$-PBA) of high molar mass can be synthesized in water thanks to a RAFT emulsion polymerization process. ${ }^{15}$ During the course of the polymerization, such asymmetric and amphiphilic copolymers form and self-assemble in situ into soft PBA corehard PAA shell particles, according to the PISA (Polymerization-Induced Self-Assembly) principle. ${ }^{16-18}$ In a previous paper $^{2}$, we reported that these core-shell latexes could be used to prepare, at room temperature, soft materials exhibiting an order of magnitude increase in stiffness, compared to non-structured films made of random $\mathrm{P}(\mathrm{BA}-\mathrm{co}-\mathrm{AA})$ copolymers latexes, while retaining an extensibility of several hundred percent. Small-Angle X-ray Scattering experiments (SAXS) and microscopy showed that the core-shell structure of the particles was retained in the film, giving rise to a percolating network of connected glassy shells. We proposed ${ }^{2}$ that the high modulus of the films was controlled by the characteristics of the shell network, such as the shell thickness and strength, while the strain at break was mainly controlled by the deformability of the particle cores. 
In this paper we focus on the mechanical properties of the films in the small and large strain regime including not only simple tensile tests but also step-cycle tests to study the reversibility of the deformation, and fracture tests with notched samples to evaluate the fracture toughness. Furthermore a variety of modifications were performed both in the RAFT emulsion polymerization step such as the incorporation of a third, hard polystyrene block to the copolymer (to yield PAA- $b$-PBA- $b$-PS), and in the film forming step by strengthening the interactions between the shells through the addition of cationic additives $\left(\mathrm{Fe}^{3+}\right.$ or polymeric amines) in the water phase.

\section{Experimental Part}

Materials. Anhydrous acrylic acid (AA, >99 \%, Fluka), N,N-dimethylaminoethyle acrylate (DMAEA, $98 \%$, Aldrich), 1,3,5-trioxane (>99\%, Fluka), ammonium hydroxide $\left(\mathrm{NH}_{4} \mathrm{OH}, 30\right.$ wt $\%$ in water, Carlo Erba), AIBN (>9\%, Fluka) and 1,4-dioxane (from VWR Rectapur) were used as received. 4,4'-Azobis-4-cyanopentanoic acid (ACPA, >98 \%, Fluka) was purified by re-crystallization from 2-propanol. Deionized water was used for all emulsion polymerizations. $n$-Butyl acrylate (BA, $99 \%$, Acros Organics) and styrene (S, $99 \%$, Aldrich) were distilled under reduced pressure before use. The RAFT agent S-1-dodecyl-S'-( $\alpha, \alpha^{\prime}-$ dimethyl- $\alpha^{\prime \prime}$-acetic acid) trithiocarbonate (TTCA) was synthesized as described elsewhere. ${ }^{19}$

Synthesis of PAA- $b$-PBA latexes. The PAA- $b$-PBA core-shell particles were synthesized as described elsewhere. ${ }^{15}$ Briefly, a poly(acrylic acid) macroRAFT agent (PAA-TTC) is first synthesized in 1,4-dioxane in presence of an asymmetric RAFT agent (TTCA ${ }^{19}$ ) and ACPA as an initiator. In a second step, the polymerization of butyl acrylate $(23 \mathrm{wt} \%)$ is implemented in batch conditions at $\mathrm{pH} 5.4\left(\mathrm{NH}_{4} \mathrm{OH}\right)$ using the macroRAFT agent as both a control agent and stabilizer. Thus, poly(acrylic acid)- $b$-poly( $n$-butyl acrylate) copolymers (PAA- $b$-PBA) are obtained (theoretical $M_{\mathrm{n}}$ of $100 \mathrm{~kg} \cdot \mathrm{mol}^{-1}$ ), which self-assemble in situ during polymerization into core-shell particles. Latexes composed of PAA- $b$-PBA core-shell particles with PAA $=3$ $\mathrm{kg} \cdot \mathrm{mol}^{-1}$ and PBA $=100 \mathrm{~kg} \cdot \mathrm{mol}^{-1}$ are referred to as standard latexes.

Preparation of PAA- $\boldsymbol{b}$-PBA- $\boldsymbol{b}$-PS latexes. The PAA- $b$-PBA- $b$-PS particles were synthesized according to reference ${ }^{15}$. Styrene $\left(0.60 \mathrm{~g}, 5.76 \times 10^{-3} \mathrm{~mol}\right)$ and AIBN $\left(1.53 \times 10^{-3}\right.$ $\left.\mathrm{g}, 9.33 \times 10^{-6} \mathrm{~mol}\right)$ are added into a degassed PAA- $b$-PBA latex $\left(5.47 \mathrm{~g}, M_{\mathrm{n}, \mathrm{PAA}}=2.3 \mathrm{~kg} \cdot \mathrm{mol}^{-}\right.$

${ }^{1}, M_{\mathrm{n}, \text { PAA- }-\mathrm{PBA}}=115 \mathrm{~kg} \cdot \mathrm{mol}^{-1}$, solid content $\left.=15 \mathrm{wt} \%\right)$. After degassing for $12 \mathrm{~h}$ at $0^{\circ} \mathrm{C}$ with 
argon bubbling, the polymerization is carried out at $70^{\circ} \mathrm{C}$ for $7 \mathrm{~h}$ in a septum-sealed flask introduced in a thermostated oil bath under gentle stirring to obtain the PAA- $b$-PBA- $b$-PS particles dispersion in water. The emulsion polymerization was quenched when reaching $90 \%$ conversion (followed by gravimetric analysis) by immersion of the flask in an ice bath. The morphology of the aqueous self-assembled copolymers was analyzed by dynamic light scattering: the particles diameter increased from $70 \mathrm{~nm}$ to $96 \mathrm{~nm}$. This was confirmed by TEM analyses. The number of particles $N_{\mathrm{p}}$ remained constant $\left(1 \times 10^{-8} \mathrm{~L}^{-1}-\right.$ see SI $)$, indicating that there was no secondary nucleation during styrene polymerization. After drying and methylation with trimethylsilyldiazomethane, the polymer was analyzed by size exclusion chromatography in THF. The number-average molar mass, $M_{\mathrm{n}}$, and the molar mass dispersity, $Ð=M_{\mathrm{w}} / M_{\mathrm{n}}$, were determined using a polystyrene $(\mathrm{PS})$ calibration curve $\left(M_{\mathrm{n}}\right.$, PAA- $b$-PBA- $b$-PS $=$ 198 kg. $\left.\mathrm{mol}^{-1}, Ð=1.8\right)$.

Preparation of PDMAEA polymer. PDMAEA was synthesized in 1,4-dioxane in presence of an asymmetric RAFT agent $\left(\right.$ TTCA $^{19}$ ) and AIBN as an initiator (See Supporting Information). $M_{\mathrm{n}}=3.7 \mathrm{~kg} \cdot \mathrm{mol}^{-1}, Ð=1.39$ (determined by SEC in DMF using a PMMA calibration).

Film formation. The latexes $(4.8 \mathrm{~mL}$ of a $23 \mathrm{wt} \%$ latex $)$ were dried in flat rectangular polydimethylsiloxane (silicone) molds $(68 \mathrm{~mm} \times 27.5 \mathrm{~mm} \times 30 \mathrm{~mm})$ for 7 days at ambient temperature and for another $12 \mathrm{~h}$ at $100^{\circ} \mathrm{C}$ under reduced pressure to eliminate remaining water, ammonia and possibly residual monomer. After drying, the acid groups of poly(acrylic acid) were fully protonated (as checked by FTIR measurements) because of the complete evaporation of $\mathrm{NH}_{3}$. For the films containing PDMAEA polymer, the PDMAEA was firstly dissolved into deionized water before being added into a PAA- $b$-PBA latex at $\mathrm{pH} 8$ (adjusted with $\mathrm{NH}_{4} \mathrm{OH} 30 \mathrm{wt} \%$ in water). The resulting latex was then dried as described above. For the films containing $\mathrm{Fe}^{3+}$ ions, an Iron(III)(acetylacetonate) solution was prepared at $6 \mathrm{mM}$ in deionized water before being added to a PAA- $b$-PBA latex. Then the resulting latex was dried as described above. 
Table 1. Block copolymer characteristics and mechanical properties by elongational rheology of the resulting films.

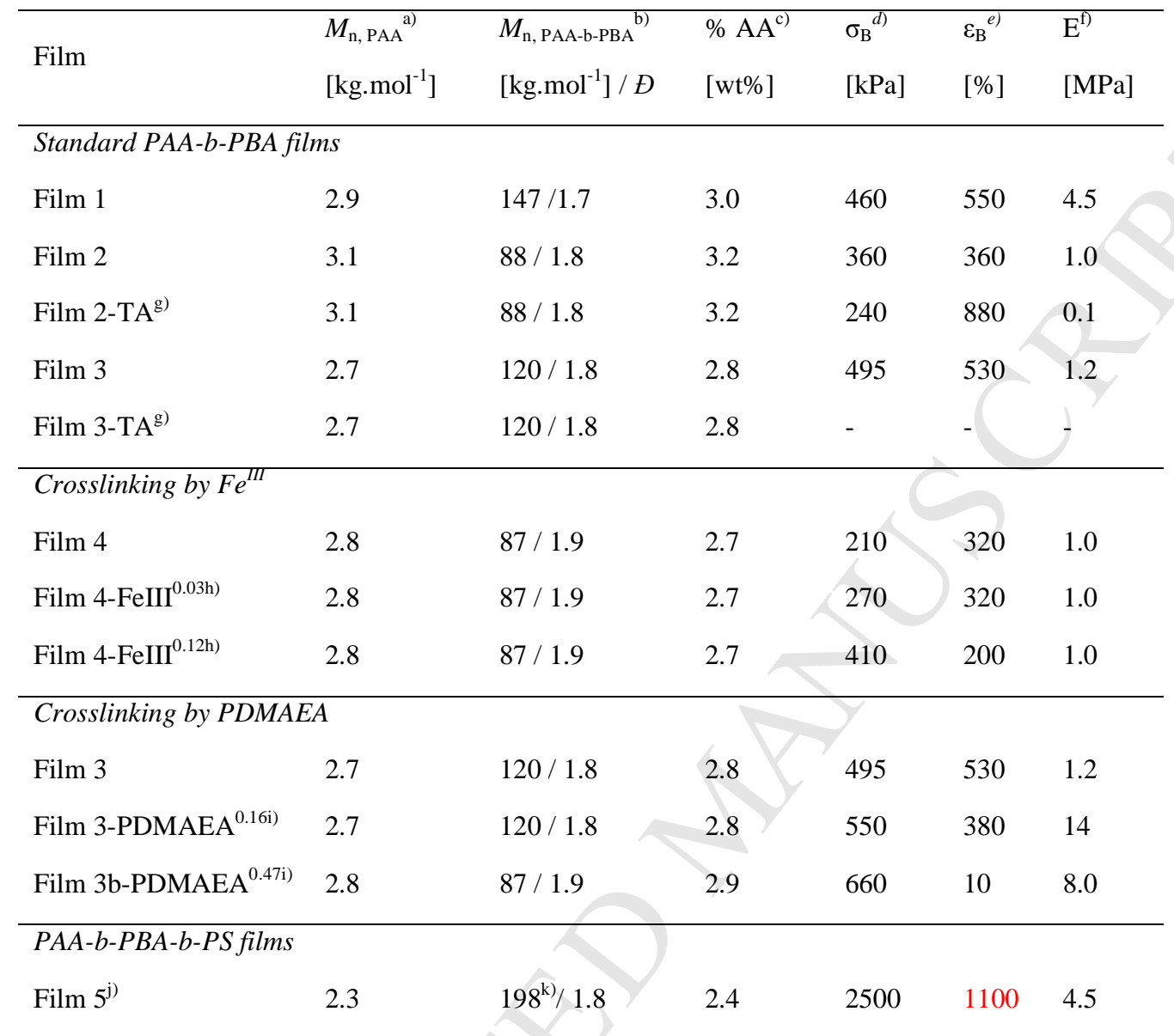

${ }^{\text {a) }}$ Determined after methylation by SEC in THF with a PS calibration. The given value corresponds to the nonmethylated polymer (subtracting the $-\mathrm{CH}_{3}$ contribution: $\left.\times 0.84\right) ;{ }^{\text {b) }}$ Determined after methylation by SEC in THF with a PS calibration. The given value corresponds to the methylated polymer; ${ }^{\mathrm{c})}$ Acrylic acid content $=\left(\mathrm{m}_{0}\right.$ $\left.(\mathrm{AA}) / \mathrm{m}_{0}(\mathrm{BA})\right) \times 100 ;{ }^{\mathrm{d})}$ Stress at break measured by elongational rheology; ${ }^{\text {e) }}$ Strain at break measured by elongational rheology; ${ }^{\mathrm{f})}$ Young's modulus measured by elongational rheology; ${ }^{\mathrm{g})}$ Control sample prepared from standard film after thermal annealing $\left(160^{\circ} \mathrm{C}\right.$ for 3 days $)$; ${ }^{\text {h) }}$ Films 4-FeIII were prepared adding 0.03 or 0.12 mol\% of $\mathrm{Fe}(\mathrm{III})$ acetylacetonate relative to AA prior to film formation; ${ }^{\text {i) }}$ Films 3-PDMAEA were prepared adding 0.16 or 0.47 mol\% DMAEA units relative to AA prior to film formation; ${ }^{j}$ ) Film 5 was prepared from a triblock PAA- $b$-PBA- $b$-PS copolymer; ${ }^{\mathrm{k})}$ The value corresponds to the PAA- $b$-PBA- $b$-PS triblock copolymer.

\section{Characterization}

Shear Rheology. Discs (diameter $\mathrm{d}=8 \mathrm{~mm}$, thickness $\mathrm{t} \sim 0.5 \mathrm{~mm}$ ) were cut out from the dried films using a punch. Shear rheology measurements were realized with a parallel plate geometry, on a Physica MCR501 rheometer from Anton Paar equipped with the Rheoplus 
software. A strain sweep was first carried out to identify the linear regime and then a temperature sweep was carried out at fixed frequency.

Tensile tests. Tensile rectangular specimens $(20 \mathrm{~mm} \times 5 \mathrm{~mm} \times 0.5 \mathrm{~mm})$ were cut from the dried films using a razor blade. Uniaxial tensile stress-strain measurements were carried out at $25^{\circ} \mathrm{C}$ using a standard tensile Instron machine (model 5565), equipped with a $10 \mathrm{~N}$ load cell and a video extensometer (model SVE) able to precisely follow the local displacement of two markers. Two black spots were drawn on the sample at approximately $10 \mathrm{~mm}$ initial distance to be tracked with the extensometer. Three replicate experiments were performed for each sample.

The force $(\mathrm{F})$ and the local elongation in the tensile direction $\left(\lambda=1 / 1_{0}\right)$ measured with the video extensometer were both recorded during the experiments. Nominal stress $\sigma_{N}$ was defined as the tensile force per unit of initial area $\mathrm{S}_{0}$ (Eq. 1):

$$
\sigma_{N}=\frac{F}{s_{0}} \quad \text { Equation } 1
$$

Cyclic extension. Incremental loading and unloading cycles were performed with the same experimental setup than tensile tests. Seven cycles with no rest period were applied between nearly $\lambda=1.2$ to $\lambda=2.1$ with incremented maximum $\lambda\left(\lambda_{\mathrm{i}+1}>\lambda_{\mathrm{i}}\right)$ and then two more cycles were performed at $\lambda=2.1$. Here again, the force $F$ and the extension ratio $\lambda$ measured by the video extensometer were recorded all along the experiment.

SAXS. The small angle X-ray scattering (SAXS) experiments were conducted at SOLEIL synchrotron on the SWING beamline in its USAXS configuration. Measurements were performed using a AVIEX CCD camera at an energy of $10 \mathrm{keV}$ with a sample-detector distance set at $6650 \mathrm{~mm}$, leading to a q-range of $0.0015-0.1 \AA^{-1}$. The tensile test apparatus was kindly lent by the UMET laboratory (initial sample length $=6 \mathrm{~mm}$, strain rate $=0.1 \mathrm{~s}^{-1}$ ).

Elongational rheology. Tensile rectangular specimens (20 $\mathrm{mm}$ x $5 \mathrm{~mm}$ x $0.5 \mathrm{~mm})$ were cut from the dried films using a razor blade. Tensile stress-strain measurements were carried out at $25^{\circ} \mathrm{C}$ on a MCR Rheometer Series from Anton Paar, equipped with a SER extensional rheology device. This device consists of two counter-rotating drums with intermeshing gears and low-friction bearings. The sample, fixed to the drums with clamps, undergoes uniform stretching when the rotational movement of the rheometer is transferred to the drums. The extension rate was $0.06 \mathrm{~s}^{-1}$. Three replicate experiments were performed for each sample. 
Fracture experiments. Tensile rectangular specimens $(20 \mathrm{~mm} \times 5 \mathrm{~mm} \times 0.5 \mathrm{~mm})$ were cut from the dried films using a razor blade. A $1 \mathrm{~mm}$ long notch was then cut on one of the long sides of the sample with a razor blade. Uniaxial tensile stress-strain measurements of these notched samples were carried out at $25^{\circ} \mathrm{C}$ until the precrack propagated and broke the sample. The nominal stress $\left(\sigma_{N}\right)$ and the extension ratio in the tensile direction $\left(\lambda=1 / 1_{0}\right)$ measured with the video extensometer were both recorded during the experiments and the extension ratio at maximum stress was noted $\lambda_{\mathrm{F}}$. If the crack starts to propagate at a well-defined value of $\lambda=\lambda_{\mathrm{F}}$ the fracture energy at initiation can then be obtained from the integral $W\left(\lambda_{F}\right)$ of the stress strain curve of an unnotched sample stretched to $\lambda_{\mathrm{F}}$ by using the approximate analysis of Greensmith ${ }^{20,21}$ :

$\Gamma=\frac{6 W\left(\lambda_{F}\right) c}{\sqrt{\lambda_{F}}}$

Equation 2

where $c$ is the length of the notch, $\lambda_{\mathrm{F}}$ is the extension ratio at fracture of the notched sample, and $\mathrm{W}\left(\lambda_{\mathrm{F}}\right)$ is the strain energy per unit volume stored in an unnotched sample at $\lambda=\lambda_{\mathrm{F}}$. 


\section{Results and Discussion}

\section{Rheology and structure of undeformed materials}

(a)

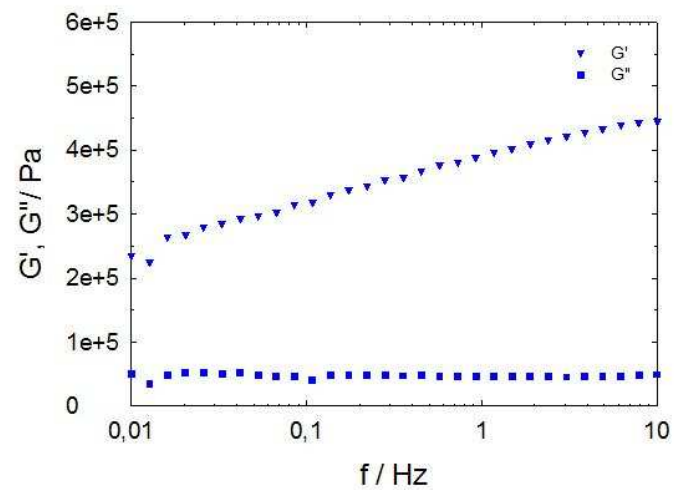

(b)

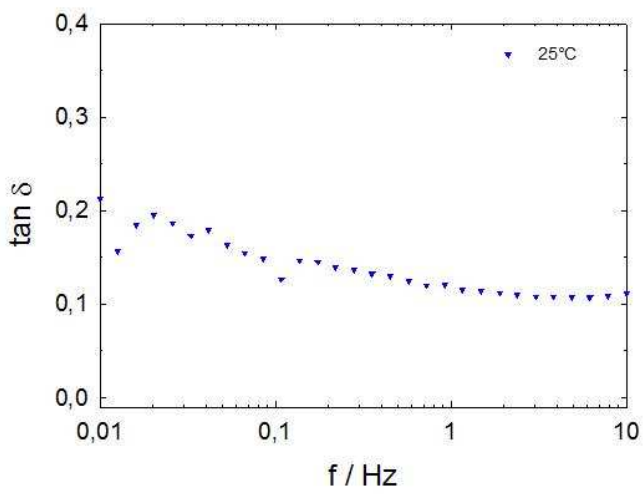

Figure 1. Linear viscoelastic properties of a nanostructured standard film (Film 1). (a) Moduli G' $(\nabla)$ and $\mathrm{G}^{\prime \prime}(\square)$ as a function of frequency at $25^{\circ} \mathrm{C}$ and (b) Tan $\delta$ as a function of frequency at $25^{\circ} \mathrm{C}(\boldsymbol{\nabla})(\varepsilon$ $\left.=0.1 \%, \mathrm{~F}_{\mathrm{n}}=0.1 \mathrm{~N}\right)$.

As reported in our previous $s^{2}{ }^{2}$, films made from PAA- $b$-PBA core-shell latexes (with $\mathrm{PAA}=3 \mathrm{~kg} \cdot \mathrm{mol}^{-1}$ and $\left.\mathrm{PBA}=100 \mathrm{~kg} \cdot \mathrm{mol}^{-1}\right)$ at room temperature $\left(25^{\circ} \mathrm{C}\right)$ and at $0.1 \%$ strain have clearly the response of a viscoelastic solid $(\tan \delta \sim 0.15$, see Figure 1), although no chemical crosslinker is present in the film and only $3 \mathrm{wt} \%$ of the material is glassy. At $25^{\circ} \mathrm{C}$, PBA of a molar mass of $100 \mathrm{~kg} \cdot \mathrm{mol}^{-1}$ is a viscoelastic fluid with a very strong frequency dependence of $\tan \delta$. This suggests that the glassy PAA shells form a percolating network.

Even if the nano-structured film obtained after drying the latex at room temperature is stable at ambient temperature, it is not at thermodynamic equilibrium. Figure 2 shows G' and G' as a function of temperature at a fixed frequency $\left(1 \mathrm{rad}_{\mathrm{s}}{ }^{-1}\right)$. During the heating ramp, the elastic modulus is almost independent of temperature until about $110^{\circ} \mathrm{C}$ and then drops abruptly at around $120^{\circ} \mathrm{C}$ ( 1 decade loss). This modulus drop is irreversible as shown by the cooling ramp which is very different from the heating one. It is interesting to note however that even if the modulus drops one decade, the material remains a viscoelastic solid at small strains. 
(a)

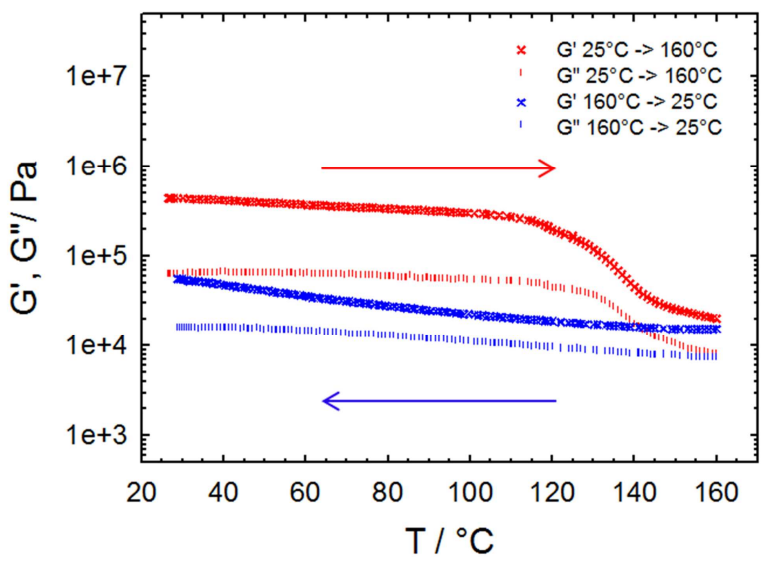

(b)

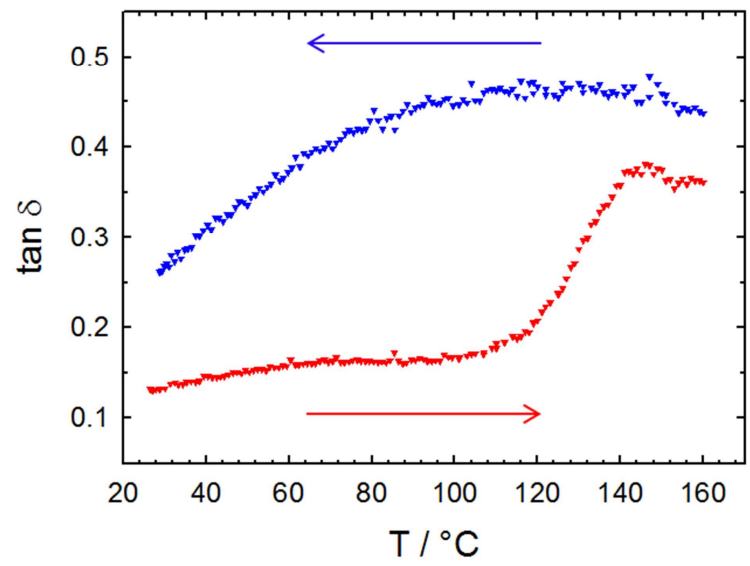

Figure 2.a) Elastic and loss moduli versus temperature for the nanostructured standard film (Film 1), b) value of $\tan \delta$ at $\omega=1 \mathrm{rad} . \mathrm{s}^{-1}\left(\varepsilon=0.1 \%, \mathrm{~F}_{\mathrm{n}}=0.1 \mathrm{~N}, 1^{\circ} \mathrm{C} \cdot \mathrm{min}^{-1}\right)$. The heating step is marked in red, the cooling step in blue.

Since the polymers are not reactive, this loss in modulus must result from a change in the film structure, which is confirmed by small angle X-ray scattering experiments. Before annealing, a well-defined interparticle distance is clearly observed in SAXS by a peak at $\mathrm{q}=0.11 \mathrm{~nm}^{-1}$ corresponding to a characteristic repeat distance of $50 \mathrm{~nm}^{2}$

After thermal annealing, the characteristic distance decreases down to $35 \mathrm{~nm}$ and the degree of long range order, shown by the presence of higher order peaks, increases. Above $120^{\circ} \mathrm{C}$ the initial organization of the glassy shells into a continuous (honey-comb like) network is most likely lost, and the equilibrium organization should become that of a very asymmetric A-B block copolymer in the bulk, i.e. small PAA spherical domains dispersed into a PBA matrix ${ }^{22}$. This new structure is no longer unusually stiff but retains some elasticity, at least at $\omega=1$ $\operatorname{rad} . s^{-1}$. 
It should be noted that the change in structure and consequently in viscoelastic properties occurs over a narrow range of temperatures, with nearly no evolution below $110^{\circ} \mathrm{C}$ in contrast to less controlled core-shell structures resulting from non-covalently linked core-shell materials described by Dos Santos et al. ${ }^{14}$ In the latter study, the elastic modulus was shown to decrease continuously during the heating ramp between $-60^{\circ} \mathrm{C}$ and $110^{\circ} \mathrm{C}$ with a loss of 2 decades in modulus, before a sharp drop was observed around $110^{\circ} \mathrm{C}$ due to the $\mathrm{T}_{\mathrm{g}}$ of the glassy component. ${ }^{14}$ This interesting property of our system must be correlated to the absence of a broad interphase of mixed composition replaced by a strong and very localized covalent link between the core and the shell chains, that was obtained thanks to the use of a controlled radical polymerization process.

In conclusion, below the $\mathrm{T}_{\mathrm{g}}$ of the PAA, the core-shell structure is stable, probably due to the strong hydrogen bonding between the PAA blocks of the shells. However above the $\mathrm{T}_{\mathrm{g}}$ of PAA, the PAA block softens and becomes mobile, leading to a film re-organization into a thermodynamically more stable structure, made of interdiffused soft PBA shells with a tiny hard PAA core.

\section{Mechanical properties at large strain of a PAA- $b$-PBA copolymer based film}

All particles discussed in the current article share the same structural features of a deformable soft core and a glassy shell, able to form a percolating network in the resulting films after drying at room temperature. The films nanostructure (shell thickness and connectivity between the shells) may be tuned via the macromolecular characteristics of the copolymers constituting the particles and the composition of the water phase (serum).

The large strain properties of the nanostructured films were characterized by elongational rheology. This technique, which is adapted to soft and slightly sticky materials, applies a uniaxial constant strain rate to the sample until fracture occurs. Figure 3 shows the nominal stress-strain curves obtained for the core-shell films, i.e. the as-cast and the annealed film. For strains below $10 \%$, the cast Film 2 presents a linear behavior, with a tensile modulus of 1.0 $\mathrm{MPa}^{2}$ For larger strains, a non-linear regime can be observed, during which the film undergoes a progressive softening. Finally, above $300 \%$, the sample breaks. This result shows that the particles must deform significantly before failure, suggesting the presence of entanglements between the block copolymers belonging to different particles. This deformation must cause a breakup of the shells into smaller fragments and consequently a drop of the modulus. In contrast, for the annealed film (Film 2-TA, Figure 3) the initial modulus is at the level of what would be expected for an entangled PBA film (0.2-0.3 MPa). 
The film extends to more than 10 times its initial length before failing, which is typically observed when acrylic acid groups are randomly incorporated in a PBA. ${ }^{23}$ Both effects suggest again a significant change in structure due to the annealing step (above the glass transition temperature of the PAA block).

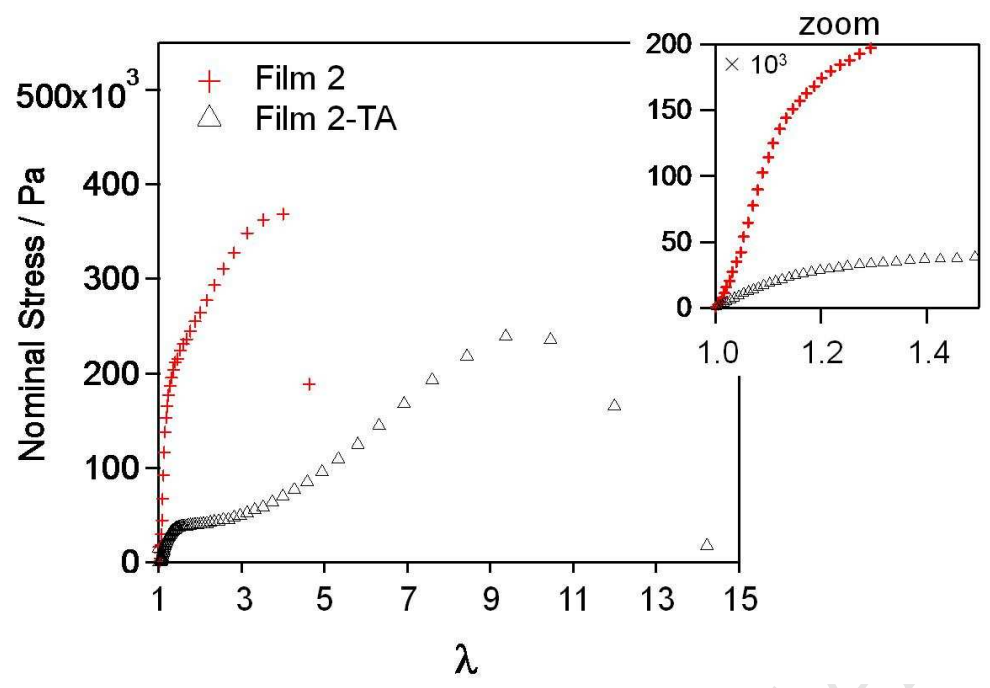

Figure 3. Nominal stress-strain curve for the structured Film 2 and the annealed Film 2-TA (temperature $=25^{\circ} \mathrm{C}$, strain rate $\left.=0.06 \mathrm{~s}^{-1}\right)$. (published in part in reference ${ }^{2}$ )

To characterize the film structural changes under strain, SAXS measurements coupled to a tensile test were performed in order to monitor changes in the internal structure of the material as a function of strain ( strain rate $=0.1 \mathrm{~s}^{-1}$ ). 
(a)

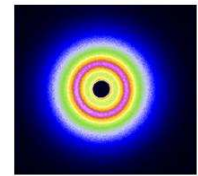

(b)

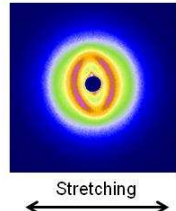

(c)
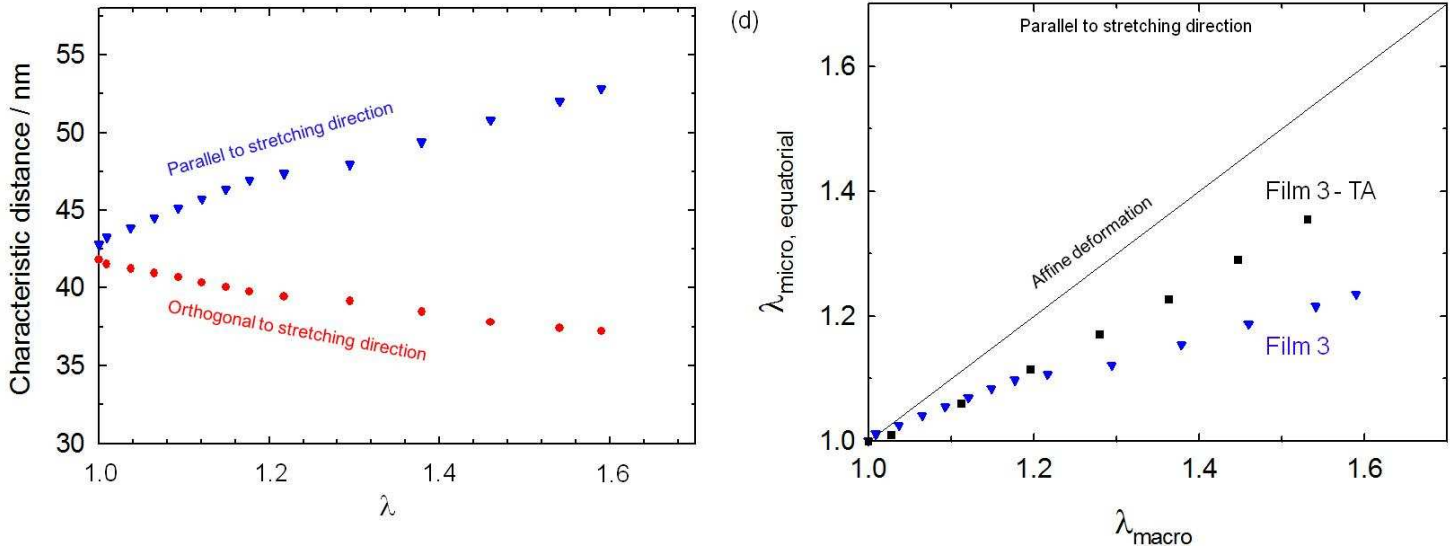

Figure 4. (a) SAXS pattern of the undeformed, nanostructured standard film (Film 3) $(\lambda=1)$,

(b) SAXS pattern obtained at $\lambda=1.55$, (c) characteristic distances parallel and orthogonal to the stretching direction plotted versus stretch, d) microscopic stretch as a function of macroscopic stretch for the pristine Film 3 and the annealed Film 3-TA.

On Figure $4 \mathrm{a}$ and $\mathrm{b}$, the diffraction patterns obtained for the undeformed film $(\lambda=1)$ and during stretching $(\lambda=1.55)$ are presented. Each pattern presents a distinct correlation peak. In the undeformed sample (Figure 4a), the peak appears at the same value of scattering vector in all directions, but as the sample is deformed, the extension of the sample induces a compression of the SAXS pattern in the direction of stretching and an expansion in the orthogonal direction (Figure 4b). In Figure 4c the characteristic distances in both directions (obtained from the $2 \pi / \mathrm{q}_{\max }$ ) are plotted as a function of the macroscopic stretch. It is shown that the characteristic distance increases parallel to the stretching direction while it decreases orthogonal to the stretching direction, as qualitatively expected from the SAXS pattern. In other words, as this characteristic distance represents the average interparticle distance, one can conclude that the particles shape evolves from an isotropic spherical shape to a compressed ellipsoid shape.

When the evolution of the microscopic deformation is plotted as a function of the macroscopic extension ratio (Figure 4d), a deviation from the affine prediction (straight line) is clearly observed. This suggests that an additional mechanism (in addition to the expected particle deformation) must occur during stretching. The observed non-affine deformation 
through particle sliding suggests that entanglements between individual particles exist, that can partially relax and reform at that particular strain rate, causing some degree of particle slippage. This might be explained by the particular core-shell structure of the particles obtained by PISA and by the relatively low molar mass of the PBA block obtained by PISA which will only result in 3-4 entanglements per chain at the most (the average molar mass between entanglements $\mathrm{M}_{\mathrm{e}}$ for PBA is around $27 \mathrm{~kg} \cdot \mathrm{mol}^{-1}$ ). In this particular synthetic approach, the particles are segregated in a pure PBA core surrounded by a thin and covalently attached pure PAA shell. As the film is deformed, the shell breaks and entanglements between PBA blocks form (and prevent brittle fracture) but they remain rather dynamic allowing some relative slippage at the particle-particle interface. Note that annealed films are deformed more affinely (entanglements are preformed and the structure is lost) but remain sub-affine.

In contrast, for classic cellular films obtained from quasi statistical copolymers incorporating acrylic acid, an affine deformation has been reported ${ }^{24}$, since much longer lived entanglements between particles may occur due to the very high molar mass obtained by conventional emulsion polymerization.

To investigate the reversibility of the structural changes upon deformation, load-unload stepcycle tests were carried out, similarly to what is typically done for crosslinked rubbers ${ }^{25}$ or semi-crystalline polymers ${ }^{26,27}$. The applied deformation history is shown in the inset of Figure $5 \mathrm{~b}$, the stress-stretch curves are reported in Figure 5a and the value of the initial modulus as a function of the applied $\lambda_{\max }$ is shown in Figure $5 \mathrm{~b}$. The curves show a significant hysteresis between the loading and unloading curves for each incremental level of stretching and the modulus E decreases as the maximum applied stretch increases. However, observing the last three cycles carried out at the same maximum stretch level, the first cycle looks very different from the next two. This suggests two energy dissipating mechanisms: a permanent damage mechanism that depends on the maximum applied strain and a viscoelastic dissipation mechanism (visible in the second and third cycle at $\lambda=2.1$ ) which will depend on strain rate and is characteristic of the material with a structure modified by the damage mechanism. This type of behavior is typical of the so-called Mullins effect in crosslinked rubbers ${ }^{25}$ where the permanent damage is correlated to changes occurring in the filler network. Similarly, for our materials, we can explain the decrease in Young's modulus by assuming that the shells initially form a connected continuous (or percolating) filler network which progressively breaks as the material is stretched (around $\lambda=1.3-1.4$, also visible in Figure 3). When all the hard PAA shells are broken, the Young's modulus stabilizes. 
(a)

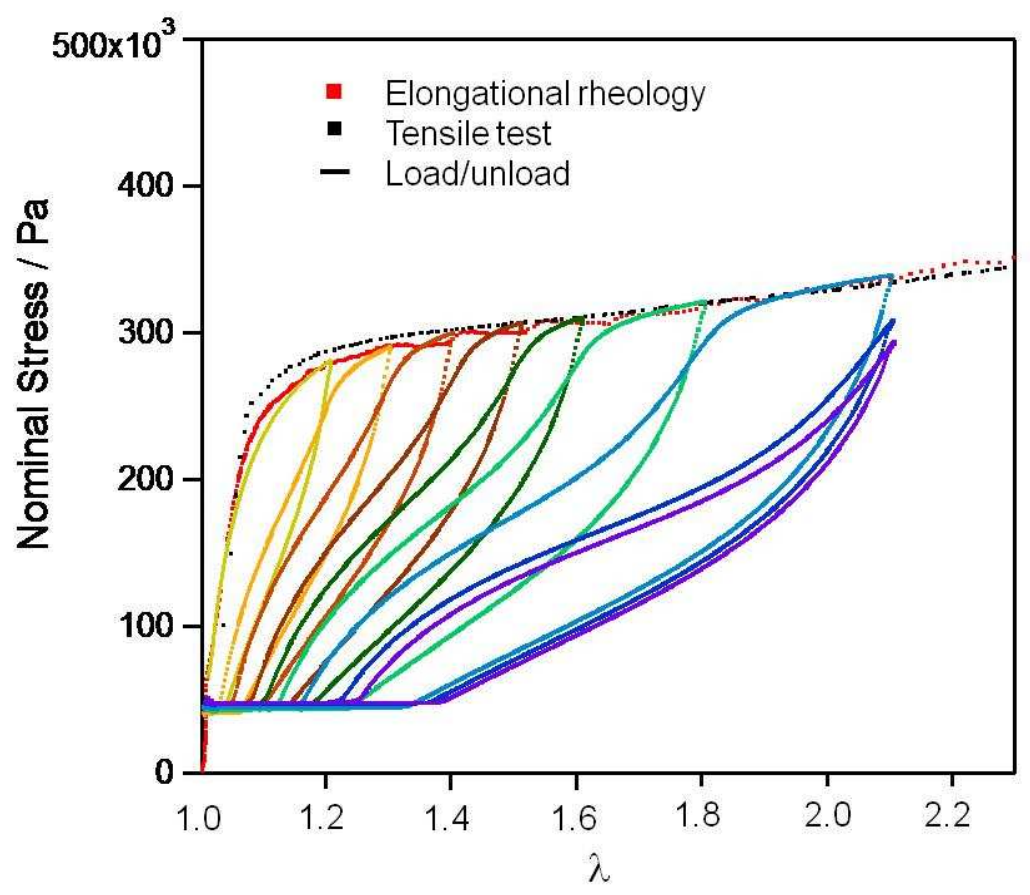

(b)

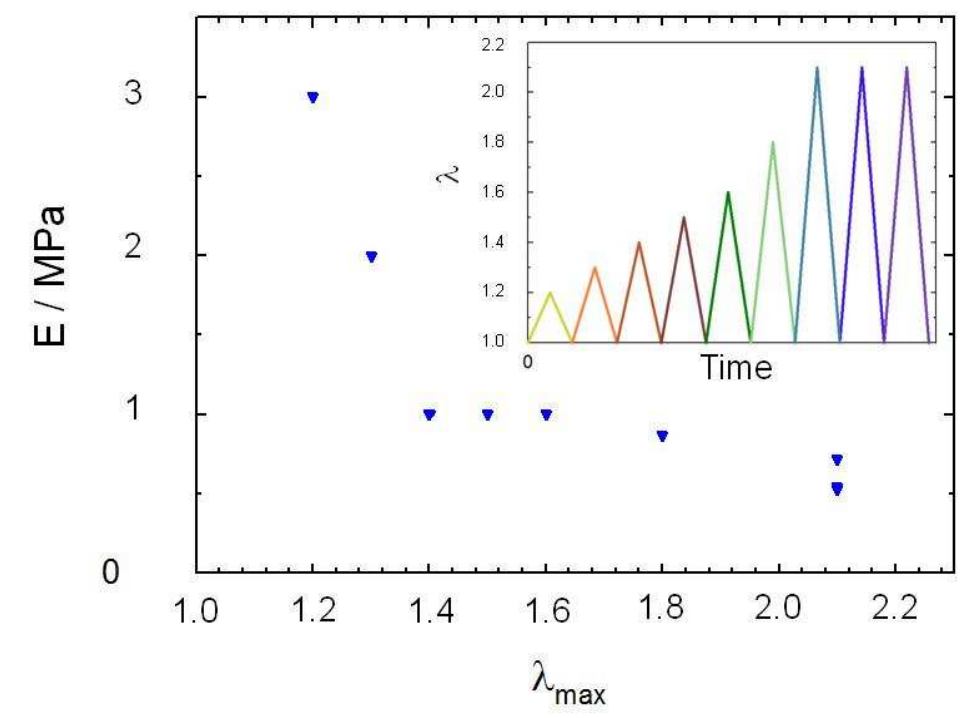

Figure 5. (a) Stress-strain curves for load-unload tensile cycles obtained for nanostructured standard film (Film 1) and (b) Young's modulus versus maximal elongation.

The combined SAXS and mechanical data allow us to propose a deformation mechanism of the nanostructured film (Figure 6). When a uniaxial deformation is applied, the particles extend in the same direction as the stretching and contract orthogonal to it. When the deformation becomes too important (10-30\%), the thin PAA shells progressively break, the continuous hard network fails, leading to a considerable drop in the Young's modulus. However this breakup of the thin shells does not lead to an overall failure. One can speculate 
that either entanglements between PBA chains in different particles exist in the undeformed film due to imperfect shells, or that PBA chains have enough time to re-entangle after the shells break. However the fact that the film can be extended to several hundred percent before breaking and this at a relatively high level of stress, suggests an additional mechanism of physical crosslinking along with entanglements, which could be created by nanoclusters of PAA chains as also observed for random $\mathrm{P}(\mathrm{AA}-\mathrm{co}$-BA) copolymers when the mole fraction of PAA reaches $30 \% .^{23}$

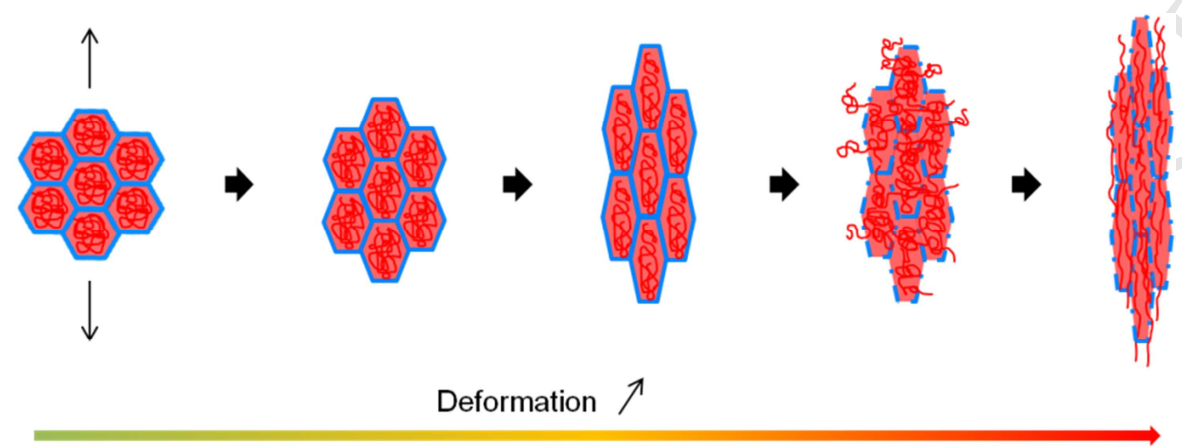

Figure 6. Proposed mechanism for the deformation of nanostructured PAA- $b$-PBA films.

In conclusion, the key parameters which control the properties of such nanostructured coreshell materials with an ultra-low volume fraction of hard shells are presumably the spatial organization (nanostructuration) of the shells in the material and their interactions. They have undoubtedly a crucial impact on the initial modulus (through the organization) and the breakup of the shells (interactions between shells). We now explore how both of these parameters can be fine-tuned. 
Interfacial physical crosslinking between particles, using $\mathrm{Fe}^{3+}$ ions or PDMAEA polymer

One strategy to delay the observed breakup of the percolating hard PAA network in our standard PAA- $b$-PBA diblock latex films is to strengthen the interfacial forces between the shells of different particles. Generally, the cohesion of the PAA network built by the PAA shells is guaranteed by the H-bonds of the carboxyl groups originating from different particles. ${ }^{2}$ Other strong known interactions are ionic bonding, through oppositely charged ions. $^{28,} 29$

To reach this objective, we have chosen to introduce water-soluble $\mathrm{Fe}^{\mathrm{III}}$ (acetylacetonate) in the water phase of the latex prior to filmification. During the film formation process, acetylacetone $\left(\mathrm{T}_{\mathrm{b}}=140^{\circ} \mathrm{C}\right.$, at ambient pressure) and ammonia evaporate, generating $\mathrm{Fe}^{3+}$ cations and carboxylate anions (Figure S3). Elongational rheology measurements carried out on films containing $\mathrm{Fe}^{3+}$ (Figure 7) showed that the ionic interfacial crosslinking clearly increased the stress at which softening is observed, without however a clear impact on the modulus, suggesting that indeed the presence of $\mathrm{Fe}^{3+}$ increases the strength of the interfaces but not the degree of organization. Yet once the PAA shells are broken into pieces, the stress remains higher for the highest $\mathrm{Fe}^{3+}$ concentration, which suggests that the presence of $\mathrm{Fe}^{3+}$ has an effect on the way the shell structure breaks up.

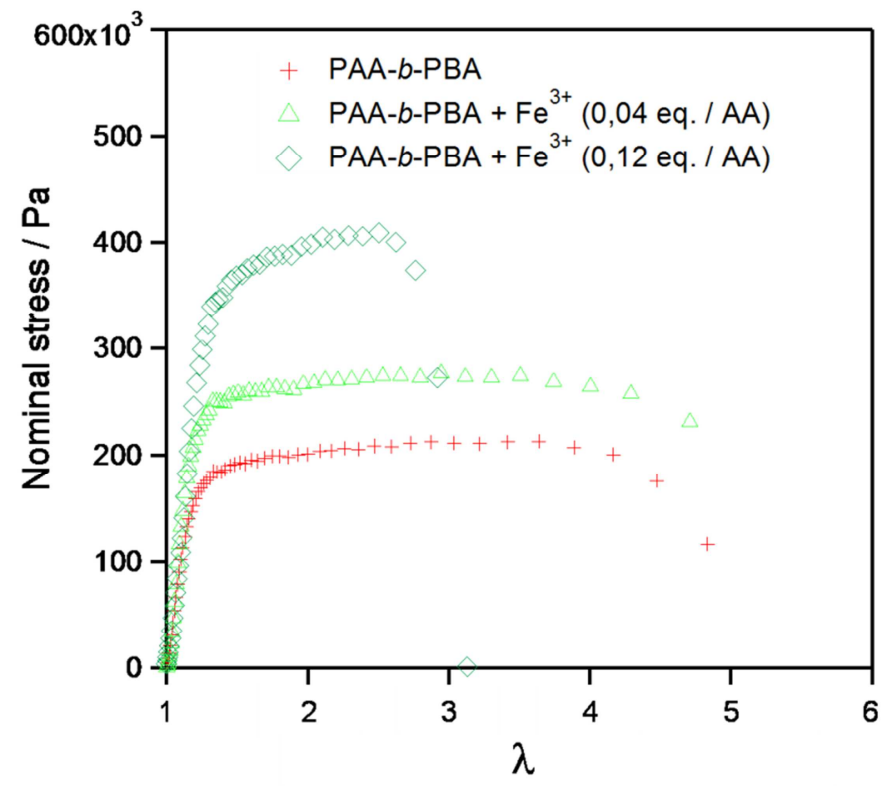

Figure 7. Nominal stress-strain curve for the nanostructured standard film (Film 4), and films formed in the presence of 0.04 (Film 4-FeIII ${ }^{0.04}$ ) and 0.12 (Film 4-FeIII ${ }^{0.12}$ ) $\mathrm{mol} \%$ (or equivalents, eq.) $\mathrm{Fe}^{3+}$ (relative to $\mathrm{AA}$ ) (temperature $=25^{\circ} \mathrm{C}$, strain rate $=0.06 \mathrm{~s}^{-1}$ ). 
Alternatively, the addition of a low molar mass water-soluble polymer possessing protonable amines as repeating units to the aqueous phase was considered. Poly $(N, N$-dimethylaminoethyl acrylate) (PDMAEA, $M_{\mathrm{n}}=3700 \mathrm{~kg} \cdot \mathrm{mol}^{-1}$ ) was chosen for its $\mathrm{pKa}$ (pKa about 6.5), close to the $\mathrm{pKa}$ of PAA. The polymer was dissolved in deionized water $(\mathrm{pH} \sim 6)$ and the solution was then added to a latex previously brought to $\mathrm{pH} 8$ with $\mathrm{NH}_{4} \mathrm{OH}$ (30wt\% in water). The idea was to keep the functional groups of the PDMAEA in their unprotonated amine form ( $\mathrm{pKa}$ 6.5) in order to avoid any destabilization of the negatively charged latex particles through ionic interactions. Upon drying, the evaporation of ammonia causes a decrease in $\mathrm{pH}$ and thus the protonation of the pendant amines of PDMAEA, which can then interact with the carboxylate groups of the PAA shells. Two films were made by introducing respectively 0.16 and 0.47 mol\% of DMAEA relative to AA.

The results of elongational rheology are displayed in Figure 8 compared to a standard film containing no PDMAEA. The film with the highest amount of PDMAEA (DMAEA/AA = $0.47)$ was brittle and stiff $\left(\mathrm{E}=8 \mathrm{MPa}, \varepsilon_{\mathrm{R}} \sim 10 \%\right)$. Reducing the amount of positive charges $(\mathrm{DMAEA} / \mathrm{AA}=0.16)$ in the latex resulted also in a very stiff film $(\mathrm{E}=14 \mathrm{MPa})$ which however surprisingly retains extensibility through a plastic yielding and a necking process. Since the $\mathrm{T}_{\mathrm{g}}$ of the PDMAEA is only about $20^{\circ} \mathrm{C}$, the mechanical stiffening at small strain must be due to the ionic interactions between the PAA and the PDMAEA rather than to $\mathrm{Tg}$ effects and the presence of the PDMAEA must also cause a stiffening at very large strain which causes the stable necking.

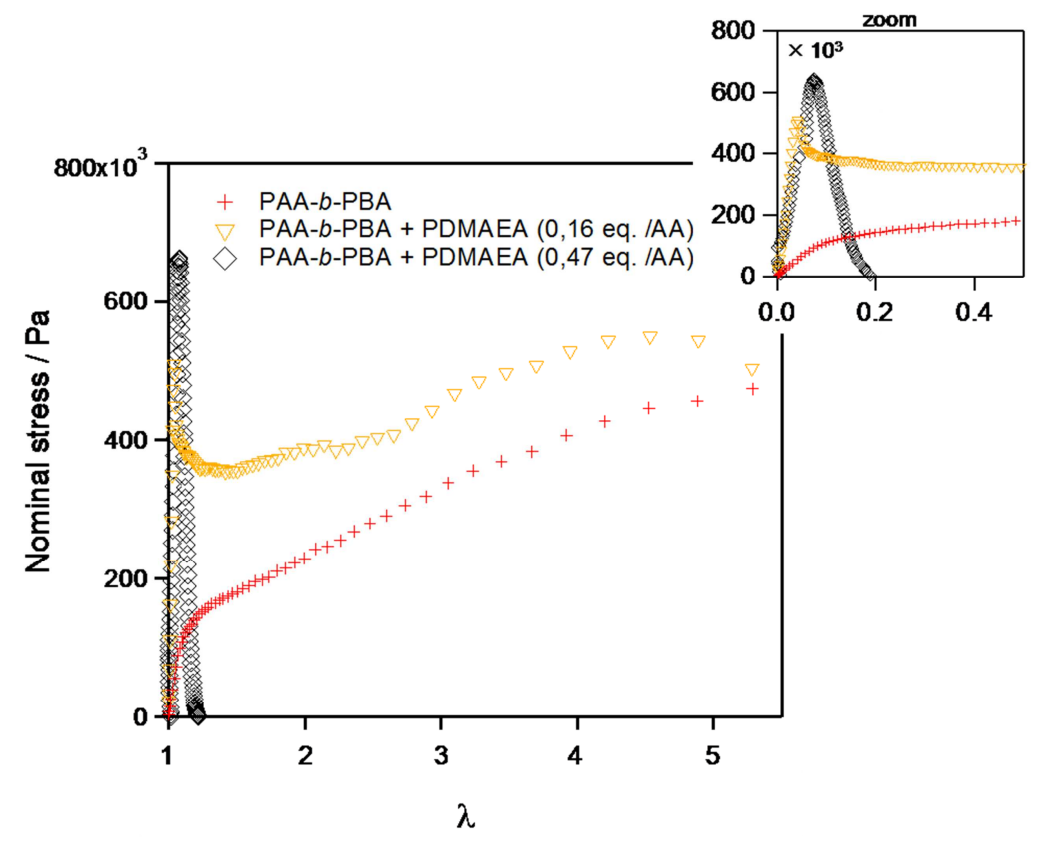


Figure 8. Nominal stress-strain curve for the nanostructured standard film (Film 3), and films formed in the presence of 0.16 (Film 3-PDMAEA ${ }^{0.16}$ ) and 0.47 (Film 3-PDMAEA ${ }^{0.47}$ ) mol\% (or equivalents, eq.) DMAEA (relative to AA) (temperature $=25^{\circ} \mathrm{C}$, strain rate $=0.06 \mathrm{~s}^{-1}$ ).

\section{Physical crosslinking with a triblock copolymer PAA-b-PBA-b-PS}

A further strategy to stabilize the nanostructure during deformation was to attach a glassy and hydrophobic block at the $\omega$-end of the PAA- $b$-PBA diblock, creating therefore nanoparticles which contain additional hard domains in their core. PAA- $b$-PBA- $b$-PS triblock copolymer $\left(\right.$ with $M_{\mathrm{n}}(\mathrm{PAA})=2.3 \mathrm{~kg} \cdot \mathrm{mol}^{-1}, M_{\mathrm{n}}(\mathrm{PAA}-b-\mathrm{PBA})=115 \mathrm{~kg} \cdot \mathrm{mol}^{-1}$ and $M_{\mathrm{n}}(\mathrm{PAA}-b-\mathrm{PBA}-b-\mathrm{PS})=$ $198 \mathrm{~kg} \cdot \mathrm{mol}^{-1}$, determined by SEC, Figure S1) latexes were thus synthesized by seeded RAFT emulsion polymerization using reactive PAA- $b$-PBA-TTC latexes. ${ }^{14}$ TEM imaging confirmed the formation of spherical sub-100nm particles, that did not melt any more under the TEM electron beam confirming the presence of a hard segment in the particles (Figure S2). The polystyrene segment is glassy and immiscible with both PBA and PAA. Therefore the resulting core-shell nanoparticles should incorporate small hard domains inside their soft PBA core. Although the AFM images of the resulting films (Figure 9) could not clearly reveal the presence of hard inclusions in the soft particles, they show a much better contrast than the softer materials with only $3 \%$ of hard PAA shells (which are not shown because of the low quality of the images). This suggests that the hardness of the particles has indeed changed due to the presence of the glassy PS blocks.

(a)

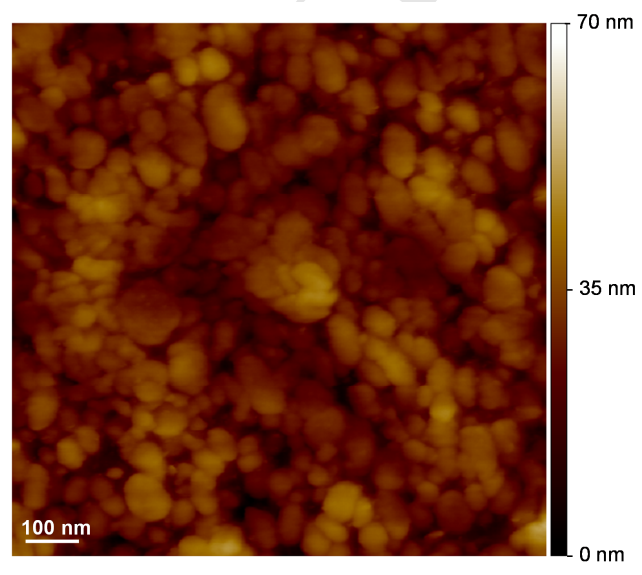

(b)

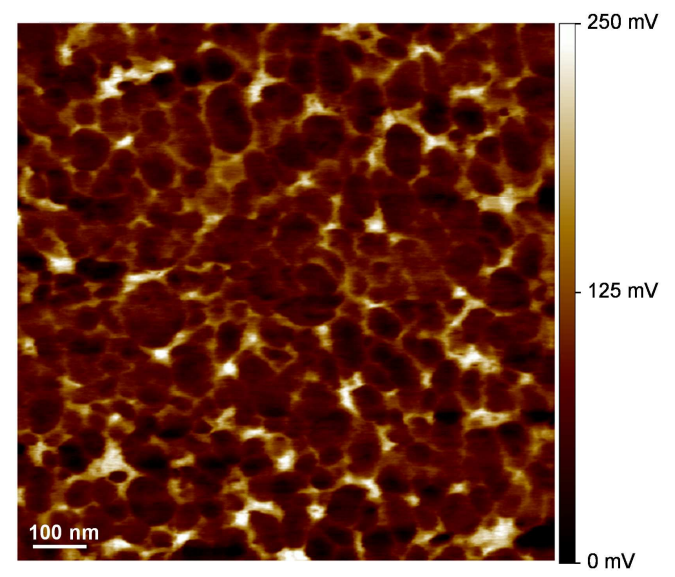


Figure 9. Atomic force microscopy image of Film 5 made from the PAA- $b$-PBA- $b$-PS latex (cross section) (a) topography image, (b) adhesion image (darker zones correspond to higher adhesion). Note that important changes in topology strongly influence the adhesion signal.

The triblock copolymer latex film (Film 5) presents indeed interesting mechanical properties in the large strain regime (Figure 10): combining a high stiffness (similar to the PAA- $b$-PBA diblock copolymer films), but a higher yield stress, where the nanostructure breaks up (>1 $\mathrm{MPa}$ ), and an increased extensibility at very high stress levels. In terms of true stress (considering the more than tenfold extension) the stress at break of this film is of the order of $25 \mathrm{MPa}$ with no chemical crosslinking.

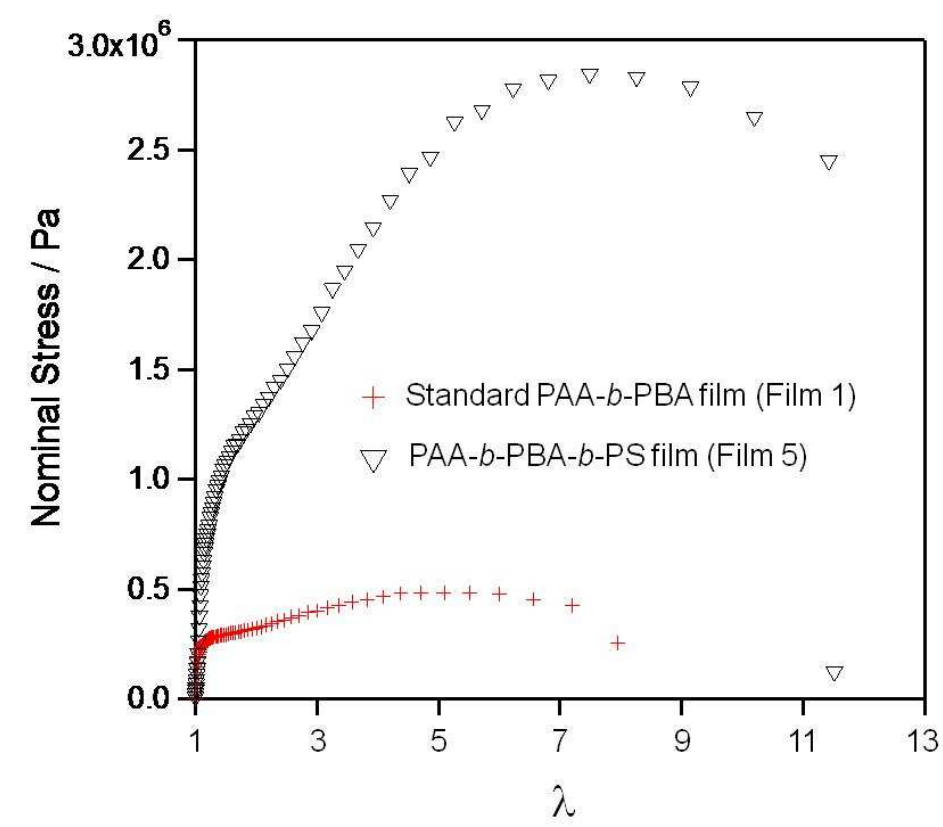

Figure 10. Stress-strain curve for the standard PAA- $b$-PBA film (Film 1) and the triblock PAA- $b$-PBA- $b$-PS film (Film 5).

Because of its outstanding stress and strain at break in simple extension experiments we investigated the mechanical properties of this last polymer in more detail. Load/unload cycles were carried out analogously to the PAA- $b$-PBA diblock copolymer latex films. Figure 11 shows the resulting stress-strain curves. Qualitatively the behavior is very similar to that of the PAA- $b$-PBA shown in Figure 5, but the stress values are much higher while retaining a reasonable recoverable deformation. This material possesses a glassy volume fraction in the 
order of $40 \%$, but the mechanical properties do not show the very distinctive strain hardening that is characteristic of thermoplastic elastomers.

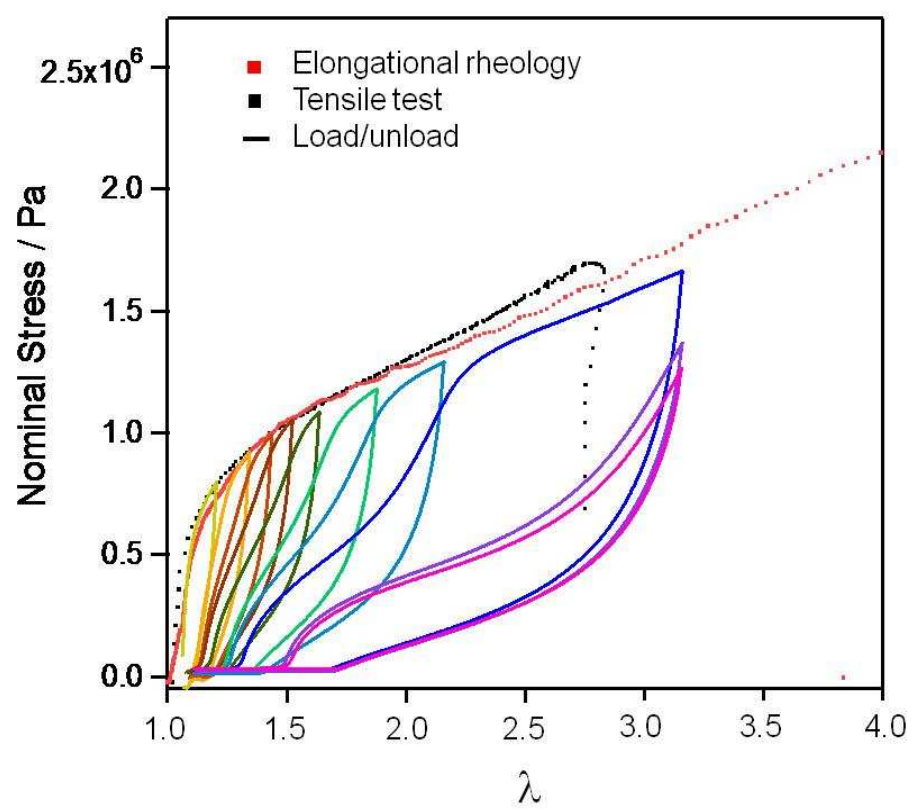

Figure 11. Stress-strain curves for load-unload tensile cycles obtained for Film 5.

We also carried out some fracture experiments on notched samples. As described in the experimental section, films containing a sharp notch introduced with a razor blade were stretched uniaxially. The fracture energy $\Gamma$ of such a sample can be estimated by Equation $2 .^{20,21}$ 


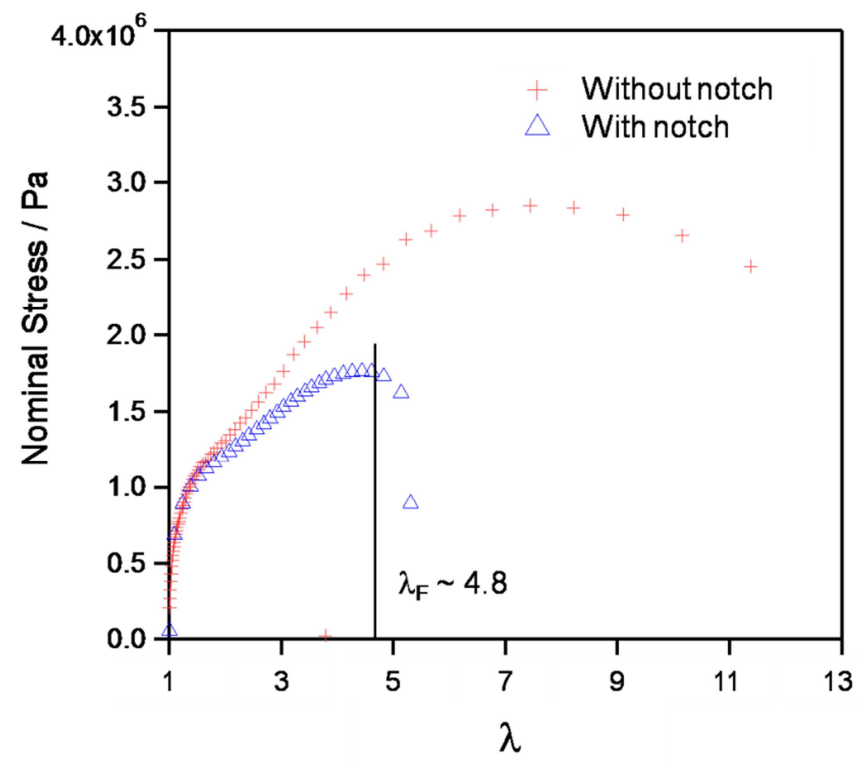

Figure 12. Fracture experiments on the PAA- $b$-PBA- $b$-PS triblock copolymer film, Film 5. Tensile stress vs. strain curve for the unnotched sample (red crosses) and the notched sample (blue triangles). The point of crack propagation is indicated for the notched sample.

Figure 12 shows the stress $v s$. strain curve for a notched and unnotched sample. The resulting fracture energy, $\Gamma=18 \mathrm{~kJ} / \mathrm{m}^{2}$, is an extremely high value for a PBA based material. This very high value is due to the very large plastic deformation needed to stretch the material as seen in Figure 11 and as reported for high toughness gels by Sun et al. ${ }^{30}$

\section{Conclusion}

We have shown in this paper the potential of the PISA method to prepare out of equilibrium nanostructured films made of block copolymer particles. These films present unique properties through the combination of high stiffness at low strain and high toughness and extensibility at large strain. The key to such excellent properties is the combination of a percolating network made of the thin glassy PAA shells (only a few percent of the total mass), which gives the material a high stiffness, and the entanglements of the soft blocks in the particles, which gives the extensibility. In uniaxial extension we always observe a low strain $(\lambda<1.3)$ region where the material is stiff $(\mathrm{E}=1-5 \mathrm{MPa})$ and elasticity is reversible, followed by a high strain region where the material is much softer but remains extensible and behaves similarly to a material made of statistical P(BA-co-AA) copolymers where interactions between PAA clusters prevent flow. Several strategies of stabilizing the nanostructure 
physically or chemically have been explored. Remarkably the most interesting and effective method was the introduction of PS segments in the particle cores via the addition of a PS block at the end of the PAA- $b$-PBA chains leading to samples with an extremely high fracture resistance while retaining a solid character with significant elasticity.

\section{Acknowledgements}

Financial support from the Ile-de-France region (M. Chenal) and the French ANR program ANR-10-BLAN-0801 Supradhesion (C. Véchambre) is acknowledged. F. Tanguy and B. Bresson are gratefully acknowledged for their help. We are indebted to the CLYM (Centre Lyonnais de Microscopiehttp://www.clym.fr) for the access to the Di3100 atomic force microscope, particularly to A. Malchère, Y. Liu, A. Descamps-Mandine and D. Albertini for their very helpful technical support. Thanks to SOLEIL synchrotron and particularly to G. Stoclet for the access to the SWING beamline.

\section{References}

1. Deplace, F.; Rabjohns, M. A.; Yamaguchi, T.; Foster, A. B.; Carelli, C.; Lei, C. H.; Ouzineb, K.; Keddie, J. L.; Lovell, P. A.; Creton, C. Soft Matter 2009, 5, 1440-7.

2. $\quad$ Chenal, M.; Rieger, J.; Vechambre, C.; Chenal, J. M.; Chazeau, L.; Creton, C.; Bouteiller, L. Macromol. Rapid Commun. 2013, 34, (19), 1524-9.

3. Shi, W.; Fredrickson, G. H.; Kramer, E. J.; Ntaras, C.; Avgeropoulos, A.; Demassieux, Q.; Creton, C. ACS Nano 2016, 10, (2), 2054-62.

4. Shi, W. C.; Hamilton, A. L.; Delaney, K. T.; Fredrickson, G. H.; Kramer, E. J.; Ntaras, C.; Avgeropoulos, A.; Lynd, N. A.; Demassieux, Q.; Creton, C. Macromolecules 2015, 48, (15), 5378-84.

5. Gurney, R. S.; Morse, A.; Siband, E.; Dupin, D.; Armes, S. P.; Keddie, J. L. J Colloid Interface Sci 2015, 448, 8-16.

6. Ducrot, E.; Chen, Y.; Bulters, M.; Sijbesma, R. P.; Creton, C. Science 2014, 344, (6180), 186-9.

7. Ahmed, S.; Nakajima, T.; Kurokawa, T.; Anamul Haque, M.; Gong, J. P. Polymer 2014, 55, (3), 914-23.

8. Rharbi, Y.; Cabane, B.; Vacher, A.; Joanicot, M.; Boue, F. Europhys Lett 1999, 46, (4), 472-8.

9. Jouault, N.; Dalmas, F.; Boué, F.; Jestin, J. Polymer 2014, 55, (10), 2523-34.

10. Mezzenga, R.; Ruokolainen, J.; Fredrickson, G. H.; Kramer, E. J. Macromolecules 2003, 36, (12), 4466-71.

11. Keddie, J. L. Mater Sci Eng R 1997, 21, (3), 101-70.

12. Winnik, M. A. Curr Opin Colloid Interface Sci 1997, 2, (2), 192-9.

13. Dos Santos, F. D.; Leibler, L. J Polym Sci Polym Phys 2003, 41, (3), 224-34.

14. Domingues Dos Santos, F.; Fabre, P.; Drujon, X.; Meunier, G.; Leibler, L. Journal of Polymer Science Part B: Polymer Physics 2000, 38, (23), 2989-3000.

15. Chenal, M.; Bouteiller, L.; Rieger, J. Polymer Chemistry 2013, 4, (3), 752-62. 
16. Lansalot, M.; Rieger, J.; D'Agosto, F., Polymerization-Induced Self-Assembly: The Contribution of Controlled Radical Polymerization to The Formation of Self-Stabilized Polymer Particles of Various Morphologies. In Macromolecular Self-assembly, John Wiley \& Sons, Inc.: 2016; pp 33-82.

17. Rieger, J. Macromol. Rapid Commun. 2015, 36, (16), 1458-71.

18. Charleux, B.; Delaittre, G.; Rieger, J.; D’Agosto, F. Macromolecules 2012, 45, (17), 6753-65.

19. Lai, J. T.; Filla, D.; Shea, R. Macromolecules 2002, 35, (18), 6754-6.

20. Greensmith, H. W. Journal of Applied Polymer Science 1963, 7, (3), 993-1002.

21. Cristiano, A.; Marcellan, A.; Keestra, B. J.; Steeman, P.; Creton, C. J Polym Sci Polym Phys 2011, 49, (5), 355-67.

22. Bates, F. S.; Fredrickson, G. H. Annu Rev Phys Chem 1990, 41, 525-57.

23. Shabbir, A.; Goldansaz, H.; Hassager, O.; van Ruymbeke, E.; Alvarez, N. J.

Macromolecules 2015, 48, (16), 5988-96.

24. Rharbi, Y.; Boue, F.; Joanicot, M.; Cabane, B. Macromolecules 1996, 29, (12), 4346-

59.

25. Diani, J.; Fayolle, B.; Gilormini, P. Eur Polym J 2009, 45, (3), 601-12.

26. Deplace, F.; Scholz, A. K.; Fredrickson, G. H.; Kramer, E. J.; Shin, Y.-W.; Shimizu, F.; Zuo, F.; Rong, L.; Hsiao, B. S.; Coates, G. W. Macromolecules 2012, 45, (13), 5604-18.

27. Deplace, F.; Wang, Z.; Lynd, N. A.; Hotta, A.; Rose, J. M.; Hustad, P. D.; Tian, J.;

Ohtaki, H.; Coates, G. W.; Shimizu, F.; Hirokane, K.; Yamada, F.; Shin, Y.-W.; Rong, L.;

Zhu, J.; Toki, S.; Hsiao, B. S.; Fredrickson, G. H.; Kramer, E. J. Journal of Polymer Science Part B: Polymer Physics 2010, 48, (13), 1428-37.

28. Roy, C. K.; Guo, H. L.; Sun, T. L.; Ihsan, A. B.; Kurokawa, T.; Takahata, M.;

Nonoyama, T.; Nakajima, T.; Gong, J. P. Adv Mater 2015, 27, (45), 7344-8.

29. Sun, T. L.; Kurokawa, T.; Kuroda, S.; Ihsan, A. B.; Akasaki, T.; Sato, K.; Haque, M. A.; Nakajima, T.; Gong, J. P. Nat Mater 2013, 12, (10), 932-7.

30. Sun, J.-Y.; Zhao, X.; Illeperuma, W. R. K.; Chaudhuri, O.; Oh, K. H.; Mooney, D. J.; Vlassak, J. J.; Suo, Z. Nature 2012, 489, (7414), 133-6. 


\section{Highlights}

- Nanostructured films containing a percolating network of PAA shells.

- High stiffness, extensibility and high fracture resistance.

- Tunable composition of block copolymer latex via the PISA approach.

- Tunable mechanical properties of the latex-derived films.

- Addition of cationic species in the serum modulates mechanical film properties. 